\title{
ULB
}

\section{A New Direct Tension Test Method for Soils and Soft Rocks}

Li, Yanrong; Guan, Fanfan; Su, He et al.

(2020)

DOI (TUprints): $\quad$ https://doi.org/10.25534/tuprints-00017374

Lizenz: $\quad$ lediglich die vom Gesetz vorgesehenen Nutzungsrechte gemäß UrhG

Publikationstyp: Artikel

Fachbereich: $\quad 13$ Fachbereich Bau- und Umweltingenieurwissenschaften

Quelle des Originals: https://tuprints.ulb.tu-darmstadt.de/17374 
Manuscript received August 21, 2019; accepted for publication July 31, 2020; published online September 9, 2020. Issue published November 1, 2020.

1 Department of Earth Sciences and Engineering, Taiyuan University of Technology, Taiyuan 030024, China (Corresponding author), e-mail: li.dennis@hotmail.com, (1) https://orcid.org/0000-00022499-5714

${ }^{2}$ Department of Earth Sciences and Engineering, Taiyuan University of Technology, Taiyuan 030024, China

3 Department of Geology and Geological Engineering, University of Mississippi, PO Box 1848, University, MS 38677, USA

${ }^{4}$ Institut und Versuchsanstalt für Geotechnik, Technische Universität Darmstadt, FranziskaBraun-Str. 7 Gebäude L5|01, 4. Stock, Raum 42564287 Darmstadt, Germany
Yanrong Li, ${ }^{1}$ Fanfan Guan, ${ }^{2} \mathrm{He}$ Su, ${ }^{2}$ Adnan Aydin, ${ }^{3}$ Mary Antonette Beroya-Eitner, ${ }^{4}$ and Hauke Zachert ${ }^{4}$

\section{A New Direct Tension Test Method for Soils and Soft Rocks}

\section{Reference}

Y. Li, F. Guan, H. Su, A. Aydin, M. A. Beroya-Eitner, and H. Zachert, "A New Direct Tension Test Method for Soils and Soft Rocks," Geotechnical Testing Journal 43, no. 6 (November/December 2020): 1317-1334. https://doi.org/10.1520/GTJ20190308

\section{ABSTRACT}

Tensile strength plays a crucial role in many engineering activities involving soils and soft rocks. Currently, several methods for tensile strength determination exist, the most common of which include the direct tension method, Brazilian test, ring test, axial fracturing test, bending test, and hydraulic fracturing test. However, outstanding problems associated with these methods, e.g., undesirable eccentric forces and damage of specimen ends, significantly affect obtained tensile strength values. To overcome these problems, we propose an alternative direct tension test method together with the newly developed apparatus. The proposed method uses an annular specimen that is tension-loaded on the inner hole. The method was evaluated through a series of tests on undisturbed soil and remolded gypsum-sand mixture specimens. For validation, comparison of results between the proposed method and the International Society for Rock Mechanics (ISRM)-suggested method was performed. Based on the results of the experimental program, the proposed method is considered more capable of and more suitable for determining the tensile strength of soils and soft rocks than the ISRM-suggested method.

\section{Keywords}

tensile strength, test method, test apparatus, hollow disk specimen

\section{Introduction}

Tensile strength plays a crucial role in determining soil and rock failure in many engineering activities, such as hydraulic fracturing of wells or boreholes, blasting and drilling of rocks, and excavation of soil or rock slopes (Goodman 1989). 
Investigation of tensile strength is therefore of great significance in engineering. However, to date, there exists no uniform standard method for the laboratory testing of tensile strength of soils and rocks (Coviello, Lagioia, and Nova 2005).

Laboratory methods for determining tensile strength are generally categorized into direct and indirect tests. Direct tension, considered the more ideal of the two test types (Mellor and Hawkes 1971), involves axial tension when a cylindrical specimen is loaded to failure along the central cross section (fig. 1A). Tensile strength is calculated by dividing the force at failure with the cross-sectional area of the specimen. The process from stretching to the destruction of the specimen can be observed in this test, providing a visual demonstration of the mechanical and failure behavior of the specimen under tension. However, the specimen preparation and apparatus operation for this test is complicated (Mellor and Hawkes 1971). For instance, the connection between the specimen and the apparatus is difficult to establish. Mechanical caps or polymer glue are usually used for this purpose (fig. 1A), but these often cause crushing of the specimen ends, especially for soils and soft rocks. The use of mechanical caps leads to anomalous stress concentrations that usually result in early rupture in these ends. Eccentric force also often appears because of misalignment between the axis of the specimen and the cap axes. Meanwhile, the specimen easily detaches from the apparatus with the use of polymer glue, leading to test failure. Direct tension test is therefore less used in laboratories for testing soils and rocks.

The difficulties associated with direct tension test have led to the development of a number of alternative indirect test methods, mainly with application to rocks. Among these are the Brazilian test (Hudson, Brown, and Rummel 1972; ISRM 1978, Suggested Methods for Determining Tensile Strength of Rock Materials), ring test

FIG. 1 Commonly used test methods for tensile strength: (A) direct tension (ISRM 1978); (B) Brazilian method (ISRM 1978); (C) ring test (Hobbs 1964); (D) axial fracturing (Dismuke, Chen, and Fang 1972; Kim et al. 2012); (E) three-point (ASTM C99/ C99M-15, Standard Test Method for Modulus of Rupture of Dimension Stone (Superseded)) and four-point bending (ASTM C880/C880M-15, Standard Test Method for Flexural Strength of Dimension Stone (Superseded)); and ( $F$ ) hydraulic fracturing (Hardy and Jayaraman 1970).

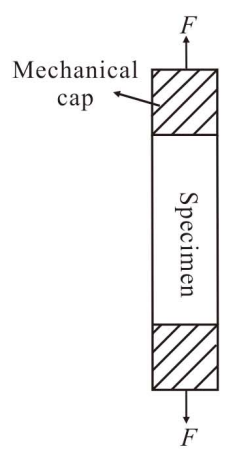

(A)

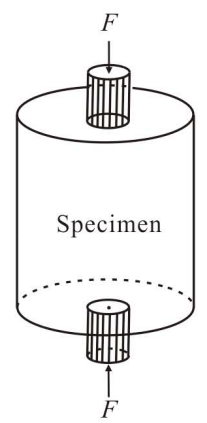

$(D)$

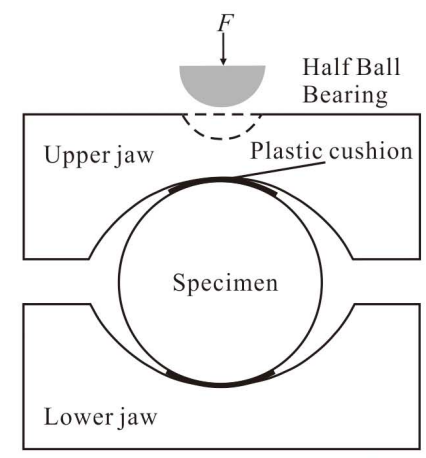

$(B)$

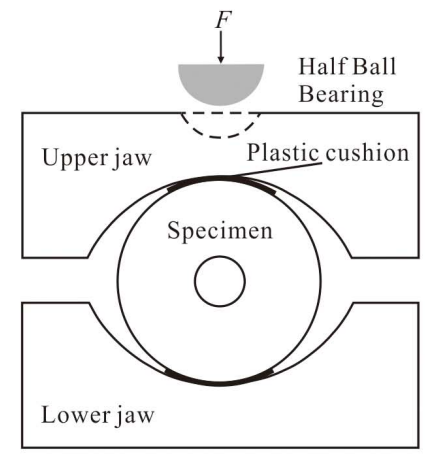

$(C)$

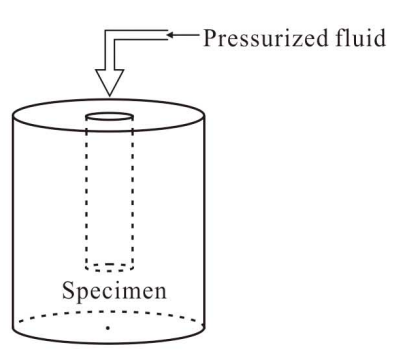

$(F)$ 
(Hobbs 1964), axial fracturing test (Dismuke, Chen, and Fang 1972; Kim et al. 2012), bending test (Khan and AlShayea 2000; He, Cao, and Evans 1990), hydraulic fracturing test (Zoback et al. 1977; Sadeghi, Nikudel, and Pahlavan 2018), and hoop test (Xu, De Freitas, and Clarke 1988).

The Brazilian test, also known as the splitting tension test, is carried out by diametrically compressing a circular plane disk (fig. 1B). Because of the simplicity of operation, this method has been used extensively for decades. The Brazilian test was recommended by the International Society for Rock Mechanics (ISRM) for testing rocks (ISRM 1978). However, like in the direct tension test, eccentric force often appears in the Brazilian test because of the difficulty of keeping the applied force on the vertical diametrical plane of the specimen throughout the test. Numerous results have also shown that primary fracture often occurs around the specimen-jaw interface, far from the center of the specimen, where the tensile stress is supposed to be at the maximum (Fairhurst 1964; Hudson, Brown, and Rummel 1972; Erarslan and Williams 2012).

The ring test overcomes the problem of primary fracture development away from the specimen center through the application of diametrical compression on a hollow disk specimen (fig. 1C; Price and Knill 1966; Hudson 1969; Hobbs 1964; Hiramatsu and Oka 1970). Experimental data from Jaeger (1967), Hardy and Jayaraman (1970), and Coviello, Lagioia, and Nova (2005) indicate that the hole at the center of the specimen enables the fracture to develop at the "proper location." However, the obtained tensile strength values far exceed those obtained from the ISRM-suggested direct tension test.

The axial fracturing test, which is based on plastic theory, was proposed by Dismuke, Chen, and Fang (1972). This test is carried out by axially loading the cylindrical pads at the two ends of a cylindrical specimen until the specimen ruptures along the axial direction (fig. 1D). The pad diameter is $0.2-0.3$ times the diameter of the specimen. Because of ease of operation, the axial fracturing test is also widely use in geotechnical engineering. However, eccentric force likewise tends to occur during loading because of the difficulty of maintaining the alignment of the cylindrical pad axes with the specimen axis. The result of the axial fracturing test is affected by many factors, including the pad diameter and specimen thickness, but uniform standards for these parameters do not exist.

The bending tests (fig. 1E), including the three-point and four-point tests, are adopted by ASTM for determining the tensile strength of variable materials (e.g., rocks, cement, and building stones). The test is performed by applying loads to one or two points in the direction normal to the axis of a simple support bar. The tensile strength is evaluated by applying the well-known Navier-Stokes formula to the fiber farthest from the neutral axis at rupture. However, there are limits to the applicability of this formula: it is only valid when the loaded sections are spaced more than two heights apart and the fracture develops in that part of the specimen (Coviello, Lagioia, and Nova 2005).

In the hydraulic fracturing test, a hollow cylindrical specimen is brought to failure by fluid pressure (fig. 1F; Hardy and Jayaraman 1970) and the tensile strength is evaluated using the elastic theory. This test is not suitable for soils and soft rocks because pressurized liquid can result in unexpected damage to the internal structure of the specimen because of the permeability of these materials.

In figure 2, results of various direct and indirect tension tests on sandstone specimens are plotted. As can be seen, the tensile strength values obtained from indirect tension tests are overestimates relative to those obtained from the direct tension test. It can also be noted that, for the same specimen, different indirect tension test methods yield different strength values (Coviello, Lagioia, and Nova 2005; Perras and Diederichs 2014).

The problems with the tensile tests outlined become even more serious when dealing with soils and soft rocks. This is because of the greater geometric tolerances that need to be accepted in the specimen preparation and the difficulty in obtaining smooth surfaces with these materials (Coviello, Lagioia, and Nova 2005). To overcome the shortcomings of the various tension test methods, we propose and present in this paper a new direct tension test. The main features, procedures, and requirements of the test are in accordance with the Chinese specification of rock test (GB/T 50266-2013, Standard for Test Methods of Engineering Rock Mass), ISRM standard (ISRM 1978), and ASTM standard (ASTM C496/C496M-11, Standard Test Method for Splitting Tensile Strength of Cylindrical Concrete Specimens (Superseded)). In the following sections, we describe this proposed method, associated apparatus, test parameters, performance evaluation, and basic requirements of the test. 
FIG. 2 Comparison between the tensile strengths of sandstone obtained from direct and indirect test methods.

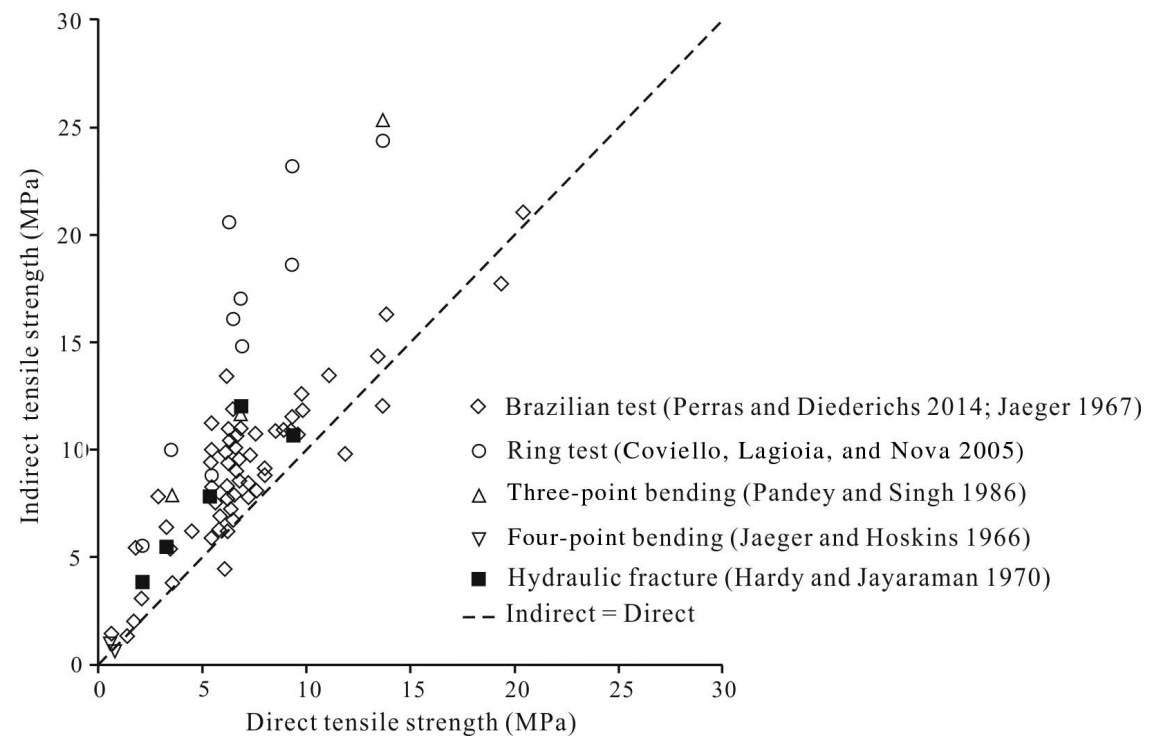

\section{Description of the Proposed Method}

\section{APPARATUS}

For the proposed method, we developed an apparatus as shown in figure 3. It adopts a servo-controlled tension system and consists of a drawbar device (fig. 3B), tension sensor, displacement sensor, and data acquisition and analysis system. The tension test frame is encased for protection. This apparatus is internationally patented.

The most important part of the apparatus is the drawbar device (fig. 3B), which is attached to the fixed frame and the lateral movable frame via connecting plates. The drawbar device consists of a left movable pull seat, left

FIG. 3 Test apparatus developed in this study: $(A)$ overview, $(B)$ drawbar device, $(C)$ left movable pull seat, $(D)$ left movable arm, $(E)$ right fixed pull seat, and $(F)$ right fixed arm.

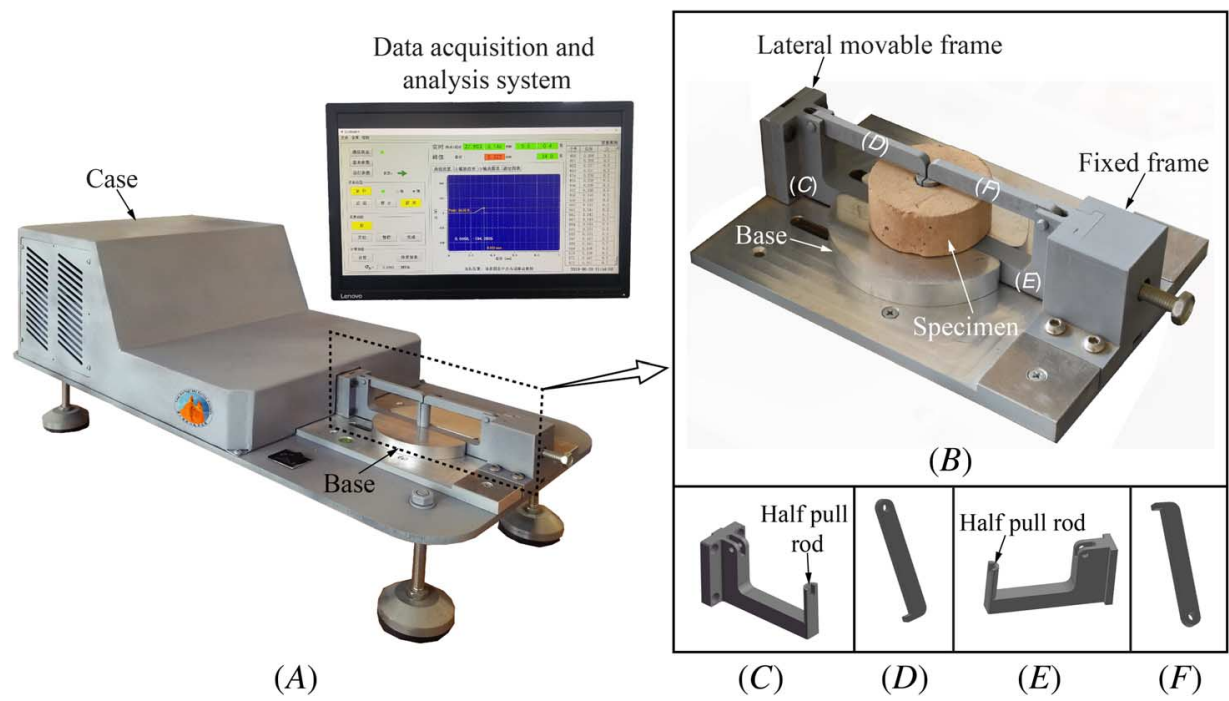


movable arm, right fixed arm, and right fixed pull seat (fig. $3 C-F)$. Each of the two pull seats has a half-pull rod that is joined to the other to form a full cylindrical rod whose diameter $(12 \mathrm{~mm})$ is equal to the diameter of the hole at the center of the specimen. The specimen is mounted on the base by sliding the inner hole onto the cylindrical rod.

During testing, the left movable pull seat is motor-driven to pull the specimen laterally apart through the half-pull rod until the specimen breaks. The left movable pull seat, right fixed pull seat, and central axis of the specimen are perfectly aligned, ensuring that fracture develops along the normal diametrical plane and that eccentric force is minimized. The surface of the base, where the specimen is seated, is smooth and thus offers minimal frictional resistance when the specimen is loaded.

The apparatus is equipped with a tension sensor (accuracy of $0.1 \mathrm{~N}$ ) that is connected to the lateral movable frame to detect the generated tension, while a linear variable displacement transducer with an accuracy of $0.001 \mathrm{~mm}$ measures the displacement of the left movable pull seat during testing. Both the tension and displacement sensors are easy to replace in case of malfunction. During the test, the data acquisition and analysis system displays in real time the tension force, displacement, and plot of tension versus displacement.

\section{SPECIMEN GEOMETRY AND PREPARATION REQUIREMENT}

The proposed apparatus requires a hollow disk specimen, as shown in figure 4. The outer diameter size was determined from laboratory investigation of size effect (see the "Size Effect" section), while the decision regarding the inner hole diameter size $(12 \mathrm{~mm})$ and thickness $(25 \mathrm{~mm})$ was largely dictated by operability and practicality, as based on actual laboratory experience. On one hand, with a smaller inner hole diameter, the pull rod is not able to withstand enough load to break the specimen. On the other hand, with a bigger diameter, it is difficult to prepare the specimen without damage or disturbance. A specimen thickness of $25 \mathrm{~mm}$ that conforms to the standard was adopted. With thicker specimens, the pull rod may deform during loading, while with thinner specimens, it is extremely difficult to drill inner holes without damage. Note that ISRM (1978) recommends that for the circular disk specimen of the Brazilian test, thickness should be approximately equal to the specimen radius. This guideline was also considered in the choice of specimen thickness for the proposed method: $25 \mathrm{~mm}$ approximates the effective specimen radius (outer radius minus the inner radius) of $24 \mathrm{~mm}$. It is also worthwhile to note that several researchers (e.g., Jaeger and Hoskins 1966; Mellor and Hawkes 1971) used a specimen thickness of 1 in $(25.4 \mathrm{~mm})$ for their ring tension test, a test with similar specimen geometry as our proposed method.

Because of the specific specimen geometry requirement of the proposed method, additional accessories for sample preparation are essential. For an intact specimen, a wire-cutting machine (fig. 5A) is needed to obtain a disk specimen and a table-based driller (fig. 5B) to make the inner hole. For a remolded specimen, a mold with a center column is needed (fig. 5C).

\section{FIG. 4}

Hollow disk specimen used in the proposed method: $T=$ thickness;

$D_{0}=$ outer diameter; and

$D_{i}=$ inner hole diameter

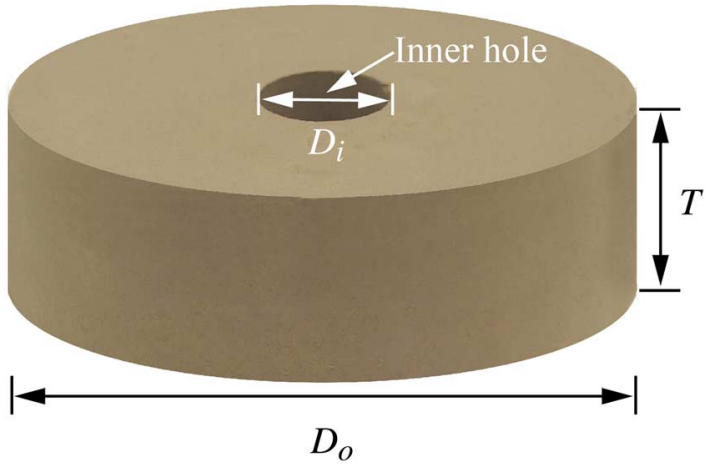


FIG. 5

Equipment for specimen preparation: $(A)$ wireless cutting machine for intact specimen, $(B)$ table-based driller to create the inner hole, and (C) self-made mold with a center column for preparing remolded specimen.

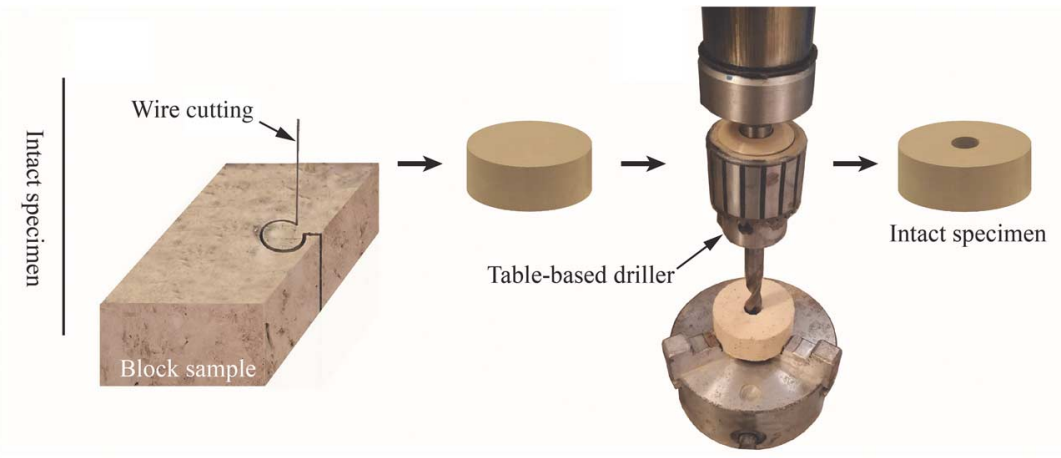

(A)

(B)

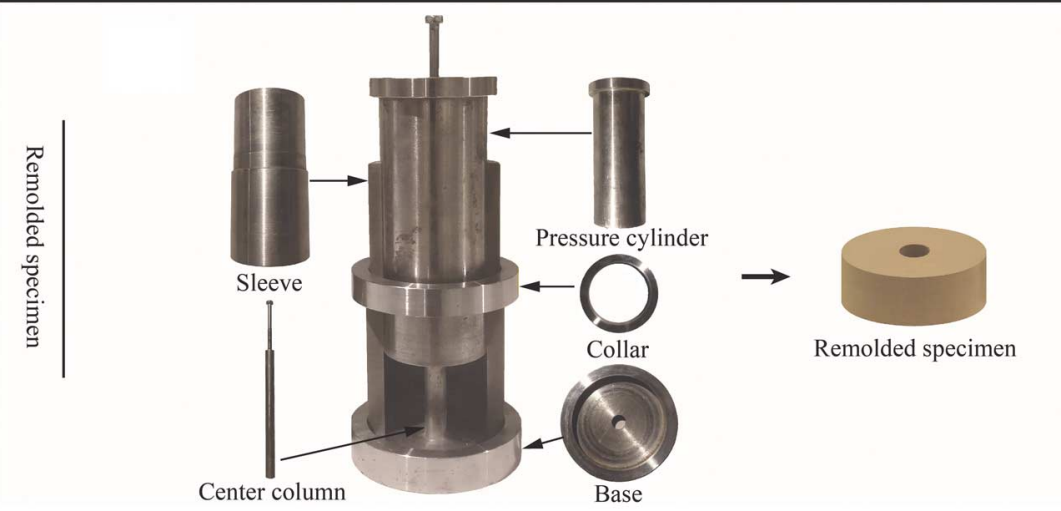

(C)

\section{EVALUATION OF TENSILE STRENGTH}

While the full-field stress expressions within a circular ring have been determined for certain types of load, such as uniformly distributed internal or external radial load, or both (Pilkey 2005), and internal/external concentrated line load (e.g., Timoshenko 1922; Billevicz 1931), no such expression exists for the loading condition of the proposed method. For the evaluation of tensile strength with the method, therefore, the average tensile stress at failure on the central diametrical plane normal to the load direction, given by equation (1), was first assumed as a valid tensile strength representation:

$$
\sigma_{t}=1,000 \frac{F_{\max }}{T\left(D_{o}-D_{i}\right)}
$$

where $\sigma_{t}$ is tensile strength in $\mathrm{kPa}, F_{\text {max }}$ is the measured peak tension force in $\mathrm{N}, D_{o}$ and $D_{i}$ are the outer and inner diameters of the specimen in $\mathrm{mm}$, respectively, and $T$ is the specimen thickness in $\mathrm{mm}$. Equation (1) assumes that the material is linearly elastic, homogeneous, and transversely isotropic.

The validity of the aforementioned equation was then confirmed through computational stress analysis. In this regard, a finite element soil model was created in Abaqus Standard 2017. The model was meshed with about 15,000 solid linear elements with reduced integration. No symmetry was introduced. The soil was modeled as a linearly elastic material with the following elastic constants: Young's modulus $=15,000 \mathrm{kPa}$ and Poisson's ratio $=$ 0.23. The loading rod was simulated as a rigid body, half of which was fixed while the other half was load-controlled and moved in the $+y$ direction. There was no bonding between the soil and the rod. 
Figure $6 \mathrm{~A}$ shows the distribution of the principal stresses on the surface of the soil specimen. The magnitude and orientation of these stresses are also shown. From the closeup view, it can be seen that along the symmetrical plane from which equation (1) is reckoned, the state of stress is purely tensional and generally uniaxial in loading direction, which are important criteria for the applicability of the equation. The full 3-D model in figure $6 B$ shows that this symmetrical plane possesses the maximum tension, in agreement with the laboratory observation of failure along this plane. To verify whether equation (1) indeed represents the average stress at failure on the symmetrical plane, the respective failure load was applied, and numerical simulation was run for each of the specimen sizes considered in this study (see the "Size Effect" section). Table 1 compares the average stress obtained from the numerical simulation and that from the analytical calculation using equation (1). It can be seen that for all the specimen sizes, the two values are in good agreement, with an error of only $1.31 \%$.

With the aforementioned results, the question that then remains is whether the use of average stress as a measure of tensile strength is valid, particularly since, as figure $6 A$ and $6 B$ show, the stresses along the symmetrical plane are nonuniformly distributed. There is considerable stress concentration at the periphery of the

FIG. 6 Results of linear elastic finite element modeling: (A) distribution of principal stresses in the soil specimen (60 mm outer diameter). Magnitude and orientation are shown. Positive sign (+) represents tension stress. Closeup view (to the right) shows that the stresses along the symmetrical plane are purely tensional and generally uniaxial in the direction normal to loading. (B) Half of the soil specimen showing mean pressure at failure load, clearly indicating that tensile stress is maximal at the symmetry plane. Stress concentration at the periphery of the inner hole is evident. Value is in $\mathrm{N} / \mathrm{mm}^{2}$; Avg., average; Max., maximum; Mid., middle; Min., minimum.

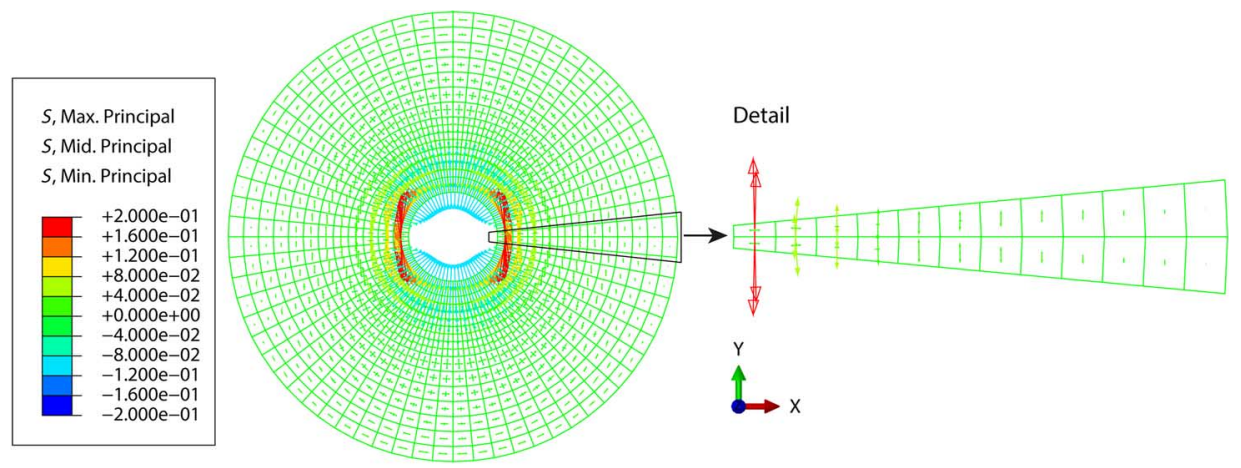

(A)

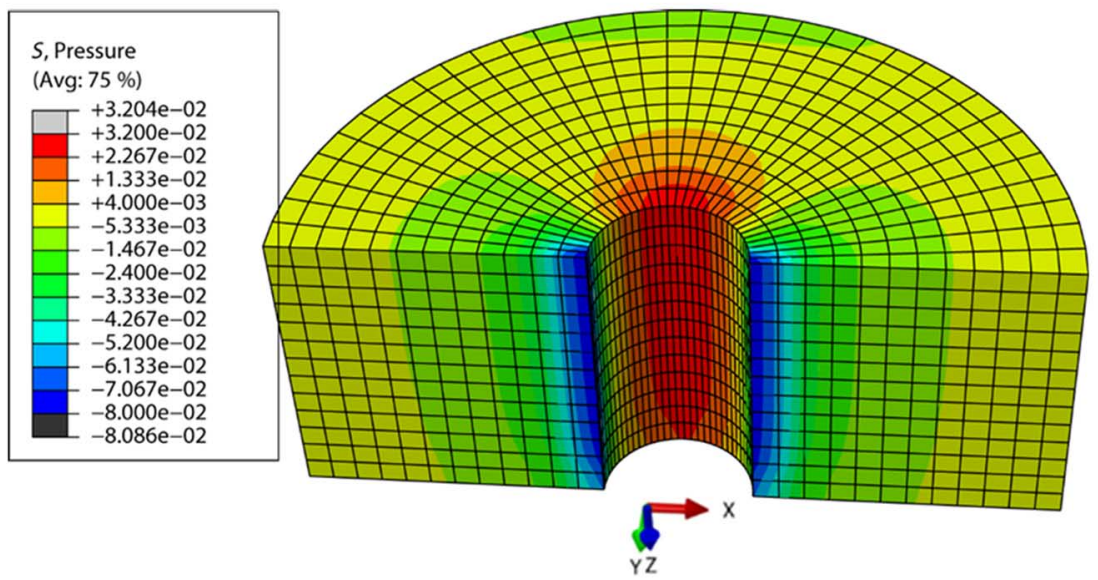

(B) 


\section{TABLE 1}

Comparison of average stress values at failure along the potential crack obtained from equation (1) and FEA for specimens of different outer diameters

\begin{tabular}{lccc}
\hline & \multicolumn{2}{c}{ Average Stress, kPa } & \\
\cline { 2 - 3 } Outer Diameter, mm & Equation (1) & FEA & Error, \% \\
\hline 40 & 23.71 & 23.92 & 0.87 \\
50 & 26.32 & 26.56 & 0.95 \\
60 & 30.00 & 30.39 & 1.31 \\
80 & 31.18 & 31.53 & 1.15 \\
100 & 31.82 & 32.23 & 1.30 \\
\hline
\end{tabular}

inner hole, which explains the initiation of failure in this area. This question cannot, however, be addressed through linear elastic finite element analysis (FEA). This is because while the said analysis can effectively depict the stress distribution in the soil specimen upon tensile loading, it cannot demonstrate the evolution of tensile stress along the potential failure plane since it does not allow the development of large strain and cracks. For this reason, discrete element modeling (DEM) was also conducted using MatDEM. The model was made up of 32,828 particles with similar properties as in FEA. Simulation was run only for the specimen geometry recommended for the proposed method (60-mm outer diameter; see the "Size Effect" section). Consistent with the FEA results, the DEM results show nonuniform stress distribution where the stresses are higher near the inner hole and lower toward the outer boundary of the specimen (fig. 7E). However, this is only at the beginning of loading. At failure point (corresponding to the peak load), the stresses become more evenly distributed (fig. 7F). Average stress at this point is $30.87 \mathrm{kPa}$, which is in good agreement with the $30 \mathrm{kPa}$ obtained from equation (1) (Table 1). Based on all the foregoing information, equation (1) is deemed a valid expression for the evaluation of tensile strength by the proposed method.

FIG. 7 Preliminary results from DEM analysis: $(A)$ stress within the specimen before tension test; $(B)$ early stage of tension test where the stress on the potential crack (the red line in $(A)$ ) is of triangular distribution (in $(E)$ ); $(C)$ the status just before the specimen fails, showing a rather even distribution with maximum, minimum, and average stresses of $42.8,19.9$, and $30.9 \mathrm{kPa}$ (in $(F)$ ), respectively, on the potential crack; (D) postfailure stage.

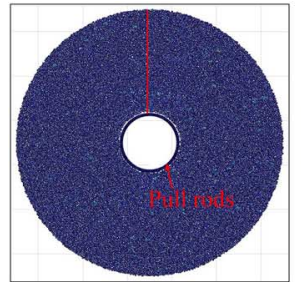

(A)

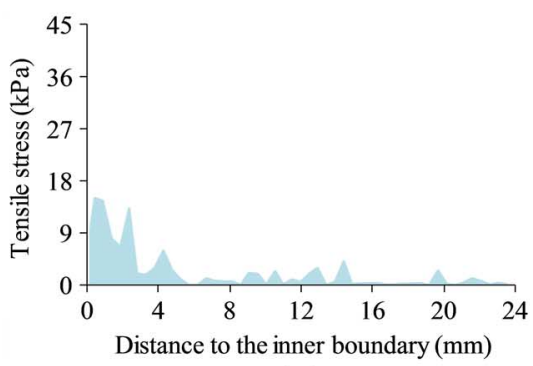

$(E)$

(B)
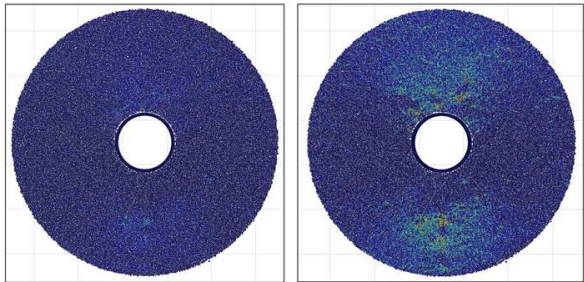

(C)

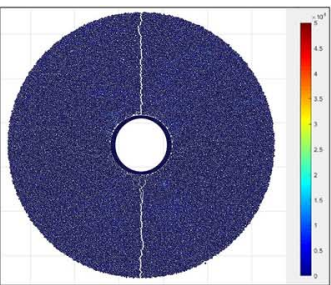

(D)

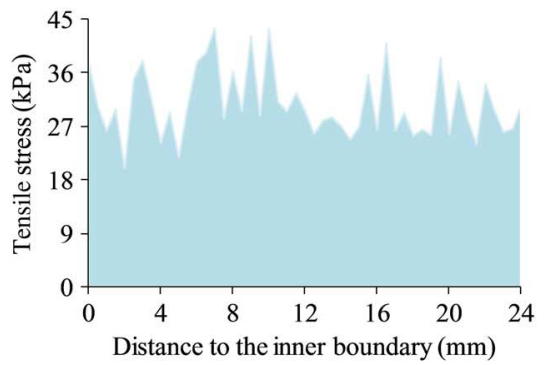

$(F)$ 


\section{Evaluation of Test Method}

\section{TEST MATERIAL AND SPECIMEN}

The soil samples used in this study were loess soil collected as blocky samples ( 30 by 30 by $30 \mathrm{~cm}$ ) from 2-m deep trial pits dug in a slope in Yuci, Shanxi Province, China. The soil has a characteristic yellowish color and porous structure. With the silt fraction accounting for $71.45 \%$ (clay fraction $11.01 \%$ and sand fraction $17.54 \%$ ) and a plastic limit of $19.2 \%$, the soil is classified according to the Chinese standard (GB/T 50145-2007, Standard for Engineering Classification of Soil) as clayey silt. The physical properties of the soil are shown in Table 2. The dry density and specific gravity were determined using the cutting ring and densimeter methods, respectively, while the liquid and plastic limits were measured using a photoelectric cone penetrometer (Nanjing Soil Instruments, GYS-2). The particle size distribution was determined using a laser particle size analyzer (Malvern Instruments, MS2000). All the aforementioned measurements were conducted following the stipulations of the Chinese Specification of Soil Test (GB/T 50123-2019, Standard for Geotechnical Test Method).

For the investigation of size and rate effects, intact soil specimens were used. A set of 25 specimens, 5 for each of the 5 outer diameters considered $(40,50,60,80$, and $100 \mathrm{~mm})$, were used for size effect evaluation, while another set of 25 specimens, 5 for each of the 5 displacement rates considered $(0.05,0.1,0.3,0.5$ and $0.7 \mathrm{~mm} / \mathrm{min}$ ), were used for rate effect evaluation. All the specimens were first oven-dried at $50^{\circ} \mathrm{C}$ to ensure uniform moisture state for tension test.

For evaluating the performance of the proposed method relative to the direct tension test, artificial gypsumsand mixture was used to ensure specimen uniformity, and therefore make the comparison meaningful. Moreover, as this artificial mixture could be prepared at a higher density and stiffness, it allows the simulation of soft rock and therefore the evaluation of the capability and performance of the apparatus over a wider range of tensile strengths. The dry density and porosity of the gypsum-sand specimens range from 1.57 to $1.82 \mathrm{~g} / \mathrm{cm}^{3}$, and the uniaxial compressive strengths range from 351 to $1,339 \mathrm{kPa}$. The properties of the standard sand, gypsum, and gypsum-sand mixture are shown in Tables 3 and 4.

To prepare the gypsum-sand specimen for the proposed method, predetermined proportions (Table 4) of standard sand, gypsum, and distilled water were placed into a container, stirred evenly, and poured into the selfmade mold. For easy demolding, the inner wall of mold was coated evenly with Vaseline. Using the static pressing method, the material was compacted, and then the mold with sample was placed in the oven at $50^{\circ} \mathrm{C}$ for $12 \mathrm{~h}$.

\section{TABLE 2}

Physical properties of the soil specimens

\begin{tabular}{lccccc}
\hline Property & $\rho_{d}, \mathrm{~g} / \mathrm{cm}^{3}$ & $G_{s}$ & $W_{L}, \%$ & $W_{p}, \%$ & $e$ \\
\hline Value & 1.34 & 2.71 & 26.7 & 19.2 & 1.172 \\
\hline
\end{tabular}

Note: $\rho_{d}=$ dry density; $G_{s}=$ specific gravity; $W_{L}=$ liquid limit; $W_{p}=$ plastic limit; $e=$ void ratio.

TABLE 3

Properties of the standard sand and gypsum used for gypsum-sand mixture

\begin{tabular}{|c|c|c|c|c|c|}
\hline Material & Property & Symbol & & Value & \\
\hline \multirow[t]{4}{*}{ Standard sand } & Moisture content & $\omega, \%$ & & $<0.2$ & \\
\hline & Silica content & $C_{s}, \%$ & & $>98$ & \\
\hline & Particle size distribution & $\mathrm{mm}$ & $<0.25$ & $0.25-0.5$ & $0.5-2.0$ \\
\hline & & $\%$ & 13 & 20 & 67 \\
\hline \multirow[t]{3}{*}{ Gypsum } & Specific gravity & $G_{s}$ & & 2.32 & \\
\hline & Solubility & $S, \mathrm{~g} / \mathrm{L}$ & & 2.0 & \\
\hline & Specific heat capacity & $c, \mathrm{~kJ} / \mathrm{kg} \cdot \mathrm{m}$ & & 0.84 & \\
\hline
\end{tabular}


TABLE 4

Properties of the gypsum-sand mixtures

\begin{tabular}{lcccc}
\hline No. & $\rho_{d}, \mathrm{~g} / \mathrm{cm}^{3}$ & $R$ & $\sigma_{u}, \mathrm{kPa}$ & $E, \mathrm{kPa}$ \\
\hline 1 & 1.57 & $6: 1: 0.6$ & 351.2 & $4.82 \times 10^{7}$ \\
2 & 1.73 & $5: 1: 0.6$ & 610.4 & $9.13 \times 10^{7}$ \\
3 & 1.77 & $5: 1: 0.6$ & 987.3 & $1.33 \times 10^{8}$ \\
4 & 1.82 & $5: 1: 0.6$ & $1,339.3$ & $1.73 \times 10^{8}$ \\
\hline
\end{tabular}

Note: $\rho_{d}=$ dry density; $R=$ ratio for standard sand, gypsum and distilled water; $\sigma_{u}=$ uniaxial compressive strength; $E=$ elastic modulus.

The sample was demolded and finally oven-dried at $50^{\circ} \mathrm{C}$ to a constant mass. For the direct tension test, the gypsum-sand mixture was prepared into cylindrical specimens of $50-\mathrm{mm}$ diameter and $100-\mathrm{mm}$ height (fig. $8 A$ ), which were then notched using a self-made groove device (fig. $8 B$ ). This created a $15-\mathrm{mm}$ wide section with a reduced diameter $(40 \mathrm{~mm})$ at the middle of the specimen (fig. $8 \mathrm{C}$ ). For each test method, four sets of gypsum-sand specimen were prepared, and each set consisted of five samples of the same dry density (Table 4).

\section{FAILURE BEHAVIOR}

To investigate the failure behavior of the specimens, a high-speed camera with a resolution of 1,280 by 1,024 pixels was used to record the tests at a filming rate of 1,000 frames per second. Figure 9 displays typical images of the specimens at different loading stages: preloading, cracking, overall failure, and postfailure stages. It can be observed that cracking is initiated at the periphery of the inner hole (fig. $9 B$ ), propagating toward the outer periphery (fig. 9C) and eventually creating a jagged fracture along the central diametrical plane perpendicular to the loading direction (fig. 9D). It usually takes about $2 / 1,000$ s between crack initiation and complete crack propagation, indicating that failure happens instantaneously and almost simultaneously with the initial cracking.

\section{SIZE EFFECT}

Tests of soil specimens with varying outer diameter $(40,50,60,80$, and $100 \mathrm{~mm})$ were carried out at a displacement rate of $0.5 \mathrm{~mm} / \mathrm{min}$ to explore the effect of specimen diameter on the measured tensile strength and determine the optimal specimen size for use with the proposed method. Note that only the outer diameter was varied in the tests since, as noted in the "Specimen Geometry and Preparation Requirement" section, the inner hole diameter size was fixed to $12 \mathrm{~mm}$ for the reason of operability and practicality.

Results are shown in figure 10A, where it can be seen that for all specimen diameters, the load-displacement curve gradually develops into a near-linear segment from the start of loading up to the peak load, after which there was a sudden force drop to zero, indicating brittle failure after the peak load (fig. 10A). Both peak tension and

FIG. 8

Preparation of specimen for ISRM direct tension

test: $(A)$ cylindrical

specimen, $(B)$ self-made

groove device, and $(C)$

specimen with an

indentation in the middle.

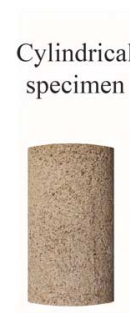

$(A)$

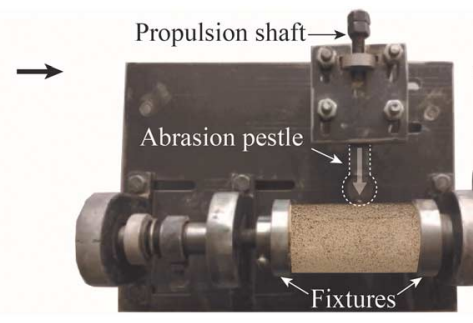

(B)
Cylindrical pecimen with an indentation

Rotary handle

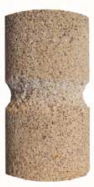

$(C)$ 
FIG. 9

Photos of the soil specimens at different loading stages: $(A)$ preloading, $(B)$ cracking, (C) overall failure, and $(D)$ postfailure stages. Images in ( $B$ ) and $(C)$ are consecutive, meaning that the crack propagation happened and ceased in 2/1,000 s.

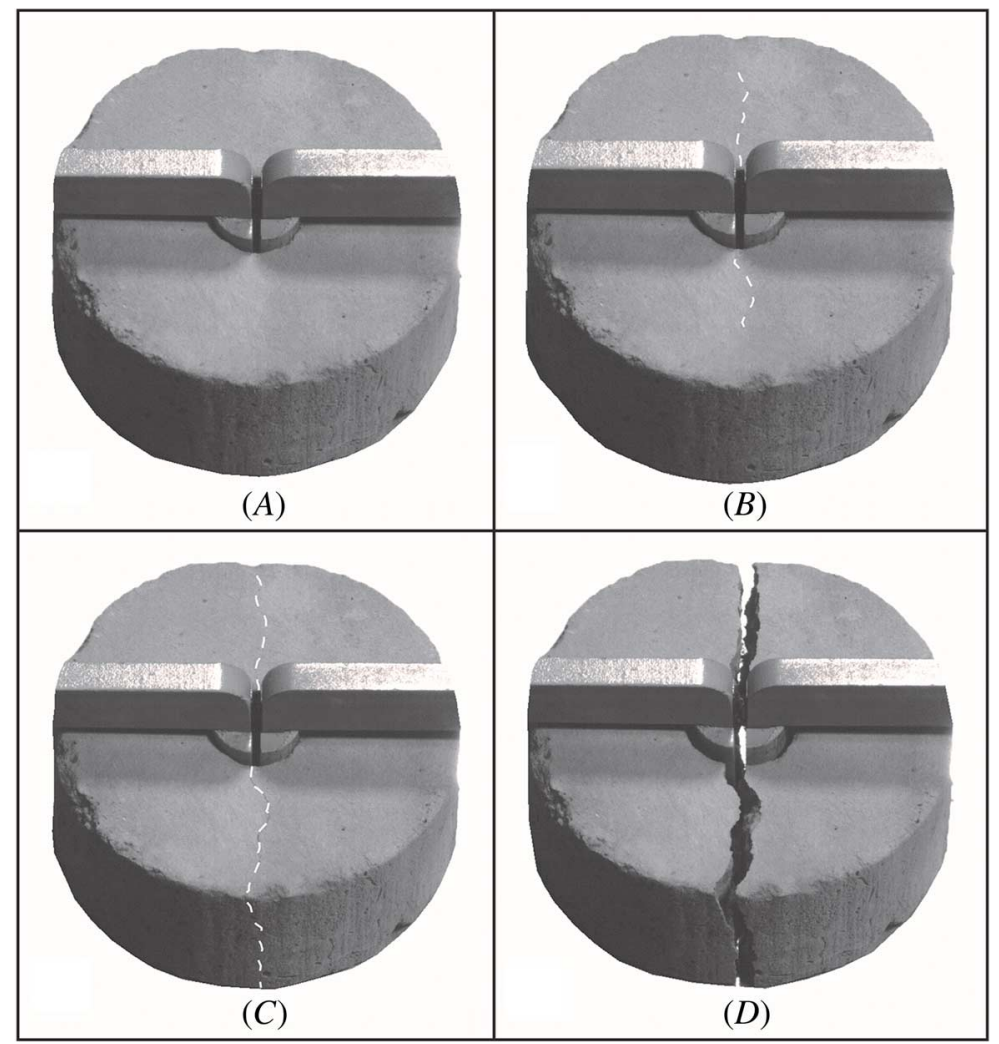

FIG. 10 Curves of $(A)$ tension force versus displacement and $(B)$ stress versus normalized displacement for different specimen outer diameters.

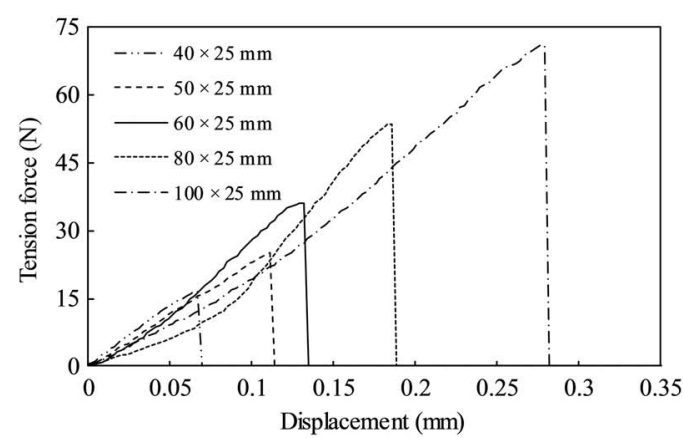

(A)

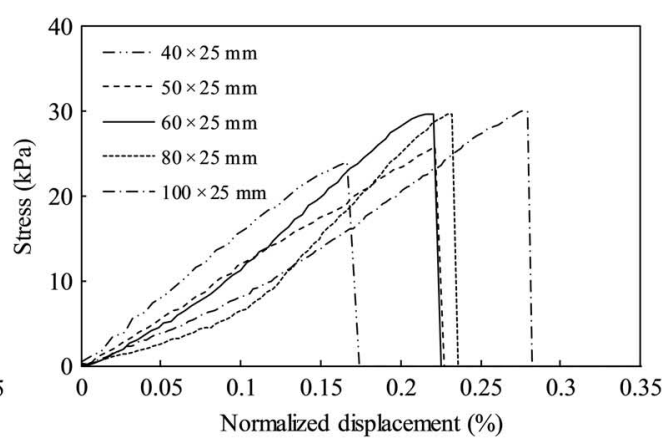

(B)

displacement increase with increased specimen outer diameter. The peak tension ranges from 16.6 to $75.3 \mathrm{~N}$ and the displacement at peak load ranges from 0.07 to $0.287 \mathrm{~mm}$.

Figure $10 B$ shows the curves of stress versus normalized displacement. The latter was calculated by dividing the measured lateral displacement by the specimen outer diameter. As can be seen, the stress at failure and the corresponding normalized displacement both fall within a narrow range, from 24 to $31 \mathrm{kPa}$ and 0.15 to $0.3 \%$, 
respectively, indicating the general independence of the stress-strain curve from specimen diameter. Deviations may be explained by inhomogeneity, potential directional property, and imperfect elasticity of the specimen.

To determine the optimal specimen diameter for the proposed test method, the simple approach suggested by Kuruppu and Funatsu (2012) was adopted. In this approach, the fracture toughness values obtained by testing specimens with a range of different sizes are plotted against diameter. If testing is done using specimens up to the largest practical size, the trend line is expected to yield the size-independent fracture toughness. Hudson (1969) used a similar approach to establish the critical hole size of the specimen for the ring tensile test, positing that the point at which the tensile strength becomes constant represents the critical hole size below which the hole has no influence anymore. Following this approach and referring to figure $11 \mathrm{~A}, 60 \mathrm{~mm}$ is determined to be the critical specimen outer diameter size for the proposed method. As can be seen, below this critical outer diameter size, a noticeable increase in tensile strength is observed with increase in the outer diameter. Beyond this, however, a further increase in the outer diameter size did not have an obvious effect in the measured tensile strength anymore. This is generally consistent with the results of Zhu and Huang (2019) on subjecting sandstone specimens to the ring tensile test, which showed that when the inner-to-outer diameter ratio is greater than 0.2 (the same ratio we have when the outer diameter is $60 \mathrm{~mm}$ since the inner diameter is $12 \mathrm{~mm}$ ), the peak load decreases rapidly. However, for the ratio in the range of 0.12 to 0.2 , the peak load undergoes only a small reduction. For the proposed method, $60 \mathrm{~mm}$ is adopted as the minimum specimen outer diameter size with which the tensile strength can be obtained free from the size effect since with larger outer diameters, the probability of occurrence of material flaw and the difficulties in specimen preparation are increased.

\section{RATE EFFECT}

Another series of tests were conducted to investigate the effect of varying displacement rates $(0.05,0.1,0.3,0.5$, and $0.7 \mathrm{~mm} / \mathrm{min}$ ) on measured tensile strength. Following the results of the "Size Effect" section, specimens with outer diameter of $60 \mathrm{~mm}$ were used. As the results in figure 11B show, the measured tensile strength increases with displacement rate. This is in good agreement with the findings of Backers and Stephansson (2012).

Figure $11 B$ also shows that the results are very unstable for the displacement rates of 0.5 and $0.7 \mathrm{~mm} / \mathrm{min}$ with coefficients of variation of 11.35 and $31.22 \%$. On the other hand, the coefficients of variation are within $8 \%$ for the displacement rates of $0.05,0.1$, and $0.3 \mathrm{~mm} / \mathrm{min}$. Of these three rates, $0.1 \mathrm{~mm} / \mathrm{min}$ (equivalent to a strain rate of 0.2 $\% / \mathrm{min}$ ) yields the most stable test results, with a minimum coefficient of variation of $4.15 \%$. Because, in addition to giving stable results, tests can be performed within a reasonable time with this displacement rate, the displacement rate of $0.1 \mathrm{~mm} / \mathrm{min}$ is recommended and adopted for use with the proposed method. This is in agreement with both ASTM D2166/D2166M-16, Standard Test Method for Unconfined Compressive Strength of Cohesive Soil, and BS EN ISO 17892-7:2018, Geotechnical Investigation and Testing-Laboratory Testing of Soil, Part 7: Unconfined Compression Test, which suggest that the strain rate should not exceed $2 \% / \mathrm{min}$ for testing rocks.

FIG. 11 Influence of $(A)$ specimen outer diameter and $(B)$ displacement rate on the measured tensile strength.

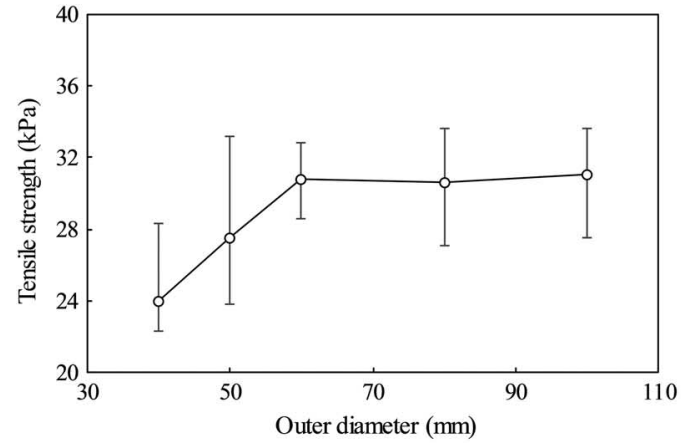

(A)

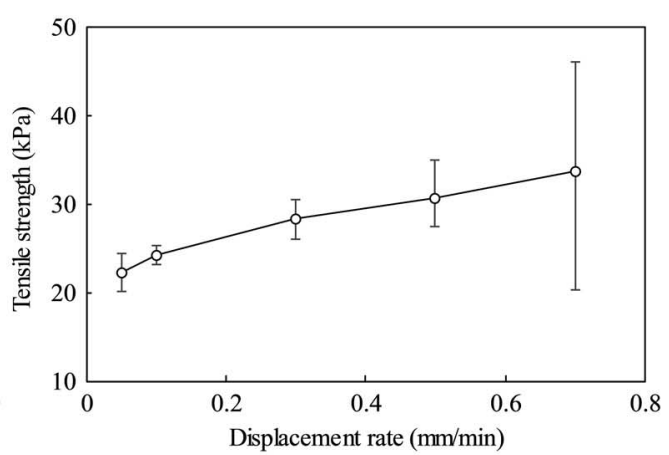

(B) 


\section{PERFORMANCE EVALUATION}

To evaluate the performance of the proposed method and the newly developed apparatus, another test campaign was conducted to compare the tensile strength obtained with the proposed method against that obtained from the ISRM-suggested direct tension method. As mentioned in the "Test Material and Specimen" section, artificial gypsum-sand specimens were used to ensure sample uniformity, thereby making the comparison more meaningful. As the mixture can be prepared to simulate soft rock, the use of the artificial mixture also allowed the capability range of the proposed apparatus to be tested. The ISRM-suggested test was conducted using a universal testing frame (fig. 12). For both test methods, a displacement rate of $0.1 \mathrm{~mm} / \mathrm{min}$ was applied following the results of the "Rate Effect" section.

As shown in figure 13, both tests resulted in the development of tension cracks along the central diametrical plane normal to load direction. Typical tension force-displacement curves from both methods are shown in figure 14, where the following can be observed: (1) the ISRM-suggested method gives a slightly greater tensile strength than the proposed method; and (2) the displacement at peak point in ISRM-suggested method is greater than that in the proposed method. The progressive failure of the specimen in the proposed method is considered responsible for the relatively low strength obtained, although like in the soil specimen, crack initiation and eventual propagation to failure happened within 2/1,000 s. The significantly bigger displacement at peak load in the ISRM-suggested method is ascribed to the relative slippage (about $0.2 \mathrm{~mm}$ as observed by using the high-speed camera) between the fixture and the specimen.

Results further show that in both methods, the tensile strength increases with increase in dry density (fig. 15A). For all tested specimens, the ISRM-suggested method gives greater values of tensile strength than the proposed method. However, for the same dry density, the coefficient of variation $\left(C_{v}=\sigma / \mu\right.$, where $\sigma$ is

\section{FIG. 12}

Setup of the modified ISRM direct tension test.

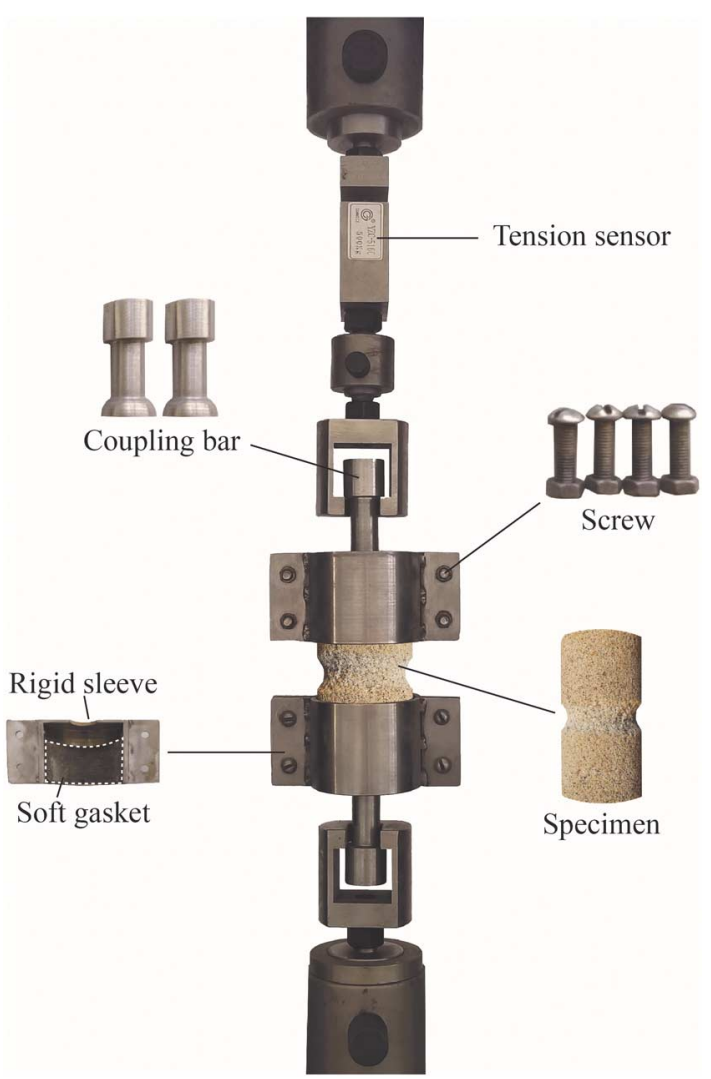


FIG. 13

Postfailure feature of the gypsum-sand specimens in the $(A)$ proposed method and (B) ISRM method.

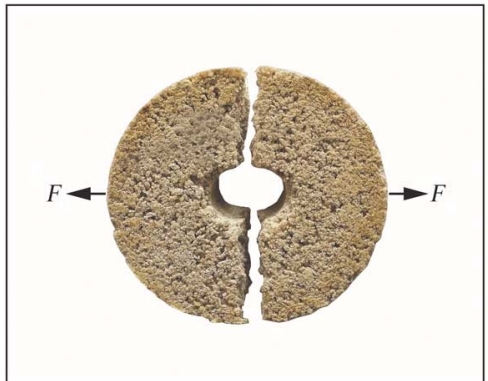

(A)

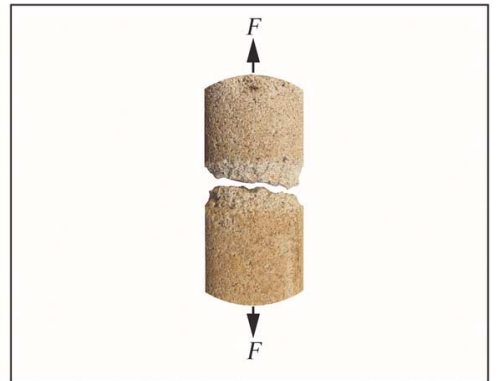

(B)

FIG. 14

Tension force-

displacement curves for the proposed and ISRM methods.

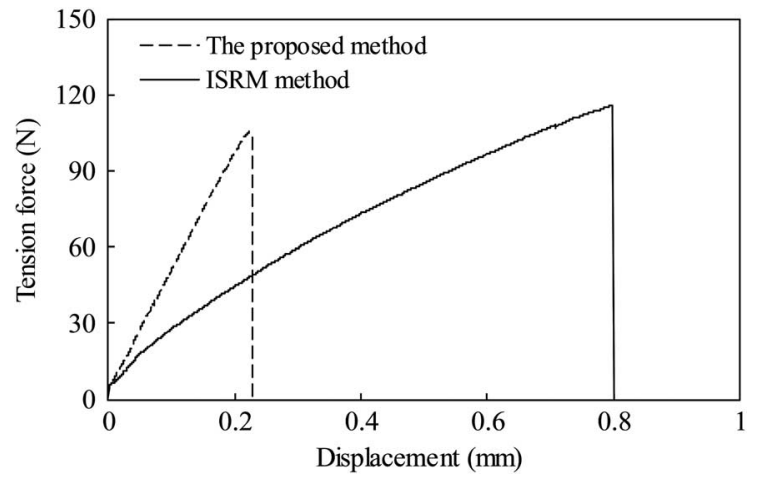

FIG. 15 Comparison between the results of the proposed and ISRM methods: $(A)$ measured strength versus dry density and $(B)$ relationship between the measured strengths from both methods.

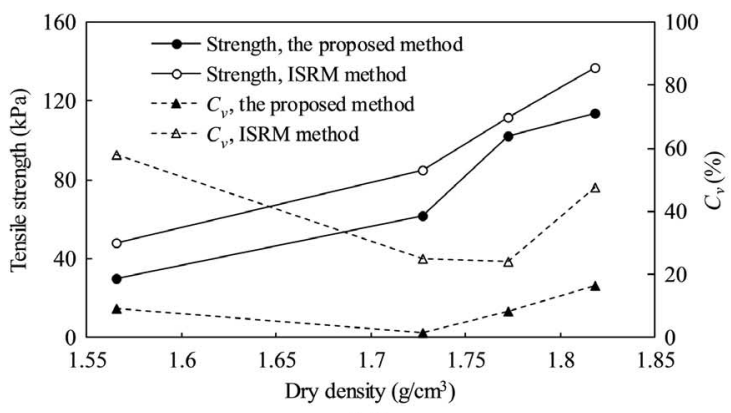

(A)

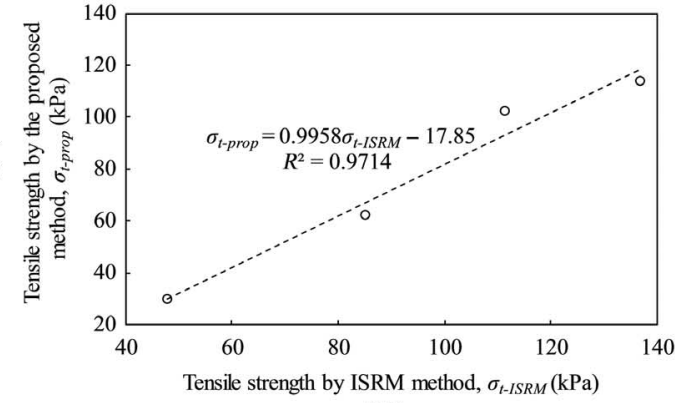

(B)

the standard deviation of the strength values and $\mu$ is the average value) of the measured tensile strengths from the proposed method is significantly lower than that from the ISRM-suggested method (fig. 15A). For instance, at a dry density of $1.57 \mathrm{~g} / \mathrm{cm}^{3}$, the $C_{v}$ of the former is 0.09 , as compared with the latter's 0.58 . This indicates that the proposed method gives more stable results than the ISRM-suggested method. In figure 15B, it can be seen that there is a tight linear relationship $\left(\sigma_{t \text {-prop }}=0.9958 \sigma_{t-I S R M}-17.85, R^{2}=0.97 ; \sigma_{\text {tprop }}\right.$ and $\sigma_{t-I S R M}$ are in $\left.\mathrm{kPa}\right)$ between 
the tensile strength values $\left(\sigma_{t-\text { prop }}\right)$ obtained from the proposed method and those from the ISRM-suggested method $\left(\sigma_{t-I S R M}\right)$. This further indicates the capability of the proposed method for the determination of tensile strength.

\section{Basic Requirements}

Based on the results and experience in the tests and considering established testing standards, we present in the following the basic requirements of the proposed method.

The end surfaces of the specimen to be tested must be flat to $0.02 \mathrm{~mm}$ and should not deviate from the plane perpendicular to the longitudinal axis of the specimen by more than $0.001 \mathrm{rad}$ or $0.05 \mathrm{~mm}$ in $50 \mathrm{~mm}$ (ISRM 1979, Suggested Methods for Determining the Uniaxial Compressive Strength and Deformability of Rock Materials). The inner and outer side surfaces of the hollow disk specimen should be smooth and free of any irregularities and straight to within $0.1 \mathrm{~mm}$ over the full thickness of the specimen. Otherwise, abnormal stress concentrations may occur at such irregularities. Proper abrasive paper may need to achieve the flatness of specimen surfaces, especially for coarse grained soft rocks.

The diameter of the test specimens must be measured to the nearest $0.1 \mathrm{~mm}$. The outer diameter $\left(D_{o}\right)$ and the inner hole diameter $\left(D_{i}\right)$ are each determined by averaging three measurements taken at a right angle to the vertical axis and at three different levels along the thickness of the specimen. The thickness $(T)$ of the specimen is measured to the nearest $1.0 \mathrm{~mm}$. These requirements are consistent with ISRM (1978) and ASTM C496/ C496M-11.

The minimum number of specimens within a set must be determined on a case-by-case basis. Usually, at least five specimens are required for testing under the same condition (ISRM 1978).

At the minimum, peak tension forces $\left(F_{\max }\right)$ must be collected during the test. However, continuous measurement of tension force (accuracy of $0.1 \mathrm{~N}$ ) and displacement $\delta$ (accuracy of $0.001 \mathrm{~mm}$ ) is recommended. With the recommended constant displacement rate of $0.1 \mathrm{~mm} / \mathrm{min}$, collection of data at a rate of four data sets per second is considered sufficient.

When the test is finished, the fractured specimen shall be preserved for in-depth observation of the failure mode. To avoid misevaluation of the tensile strength, the test shall be considered unacceptable if the plane of the crack deviates from the diametrical plane of the specimen by more than $0.05 D_{o}$. In our experiments, the unacceptable failure modes mainly fall into two categories. In the first category, specimens failed into two unbalanced pieces with irregular failure surface, as shown in figure 16A. In this case, the measured tensile strength could be twice the value obtained under acceptable failure mode. In the other category, specimens fractured into three or more pieces (fig. 16B). This case usually gave a relatively low tensile strength. About $7 \%$ unacceptable tests were

FIG. 16 Typical unacceptable failure modes for the proposed method: $(A)$ Modes I and II; (B) Modes III and IV.

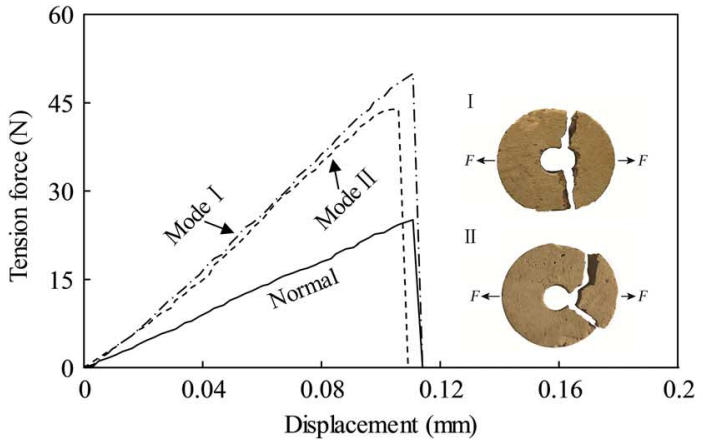

(A)

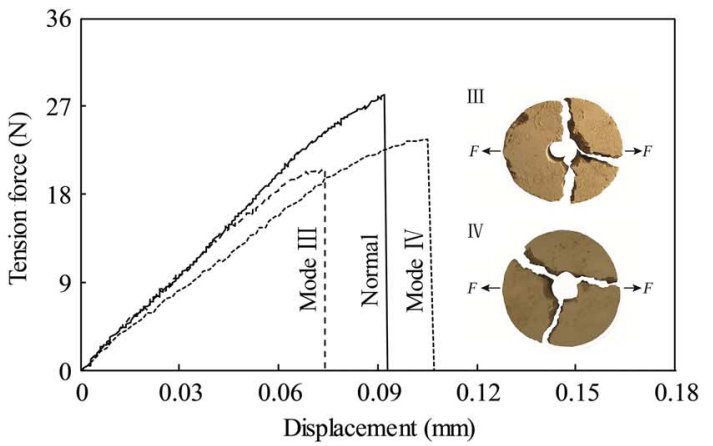

(B) 
encountered in our experiments. The rough preparation of specimen, nonstandard test operations, and inherent defects in the specimen were found to be mainly responsible for these failures.

Together with the test conditions and results, the following information needs to be recorded for each test: specimen storage and preparation procedure, moisture content and adjustment thereof, and specimen size. Any macroscopic characteristics of the specimen surfaces as well as any adjustment made with the specimen conditions shall also be reported. The surrounding environmental conditions shall also be recorded if applicable.

\section{Limitations and Outlook}

This study aims to propose a new test method and apparatus for testing the tensile strength of weak materials (soil and soft rocks). As a preliminary study, a laboratory approach was mainly used to establish the test parameters and evaluate the method's performance and capability. Thus, only an initial computational analysis was conducted. Further studies may therefore be aimed at more rigorous numerical simulations. For instance, a nonlinear FEA may be conducted to track the development of tensile stress and strain with crack propagation at failure point for further validation of equation (1). Regarding the specimen size, fixed inner hole diameter and thickness were employed in this study in consideration of actual operability and practicality and with reference to relevant standards and the work of other researchers that used the same general specimen geometry. Test results showed general agreement with the results of other researchers. This notwithstanding, exploring how the different combinations of inner diameter, outer diameter, and thickness affect measured tensile strength can be the subject of a more extensive study in the future. Further study may also focus on optimizing the stress distribution as by slight modification of specimen geometry and on developing empirical formulas to enlarge the scope of applicability of the method in terms of material type. It would also be of high interest to know how the obtained tensile strength values vary with temperature and pressure for evaluation of in situ cases. This, however, also requires a more detailed and elaborate test program.

\section{Summary and Conclusion}

To address the deficiencies of the currently existing tension test methods, especially when used for soils and soft rocks, we proposed a new direct tension test method and developed the associated apparatus that are particularly well-suited for these materials. A hollow disk specimen with outer diameter of $60 \mathrm{~mm}$, inner hole diameter of $12 \mathrm{~mm}$, and thickness of $25 \mathrm{~mm}$ is used with the proposed method and apparatus. A displacement rate of $0.1 \mathrm{~mm} /$ min is recommended to avoid possible dynamic effects during testing while still allowing the test to be performed within a reasonable time.

The specimen preparation and test operation in this new method are simple, and the eccentric force that is a common problem with the currently available methods is minimized. Performance of the conducted experiments indicated that the proposed method and apparatus are more capable of and suitable for determining the tensile strength of soils and soft rocks than other currently available methods.

\section{ACKNOWLEDGMENTS}

This study was supported by the following: Key Program of National Natural Science Foundation of China (No. 41630640), Major Program of the National Natural Science Foundation of China (No. 41790445), National Natural Science Foundation of China (No. 41877276), 2014 Fund Program for the Scientific Activities of Selected Returned Overseas Professionals in Shanxi Province, Shanxi Scholarship Council of China, Outstanding Innovative Teams of Higher Learning Institutions of Shanxi, Soft-science Fund Project of Science and Technology in Shanxi, Research Project for Young Sanjin Scholarship of Shanxi, Collaborative Innovation Center for Geohazard Process and Prevention at Taiyuan University of Technology, and Recruitment Program for Young Professionals of China. 


\section{References}

ASTM International. 2011. Standard Test Method for Splitting Tensile Strength of Cylindrical Concrete Specimens (Superseded). ASTM C496/C496M-11. West Conshohocken, PA: ASTM International, approved July 1, 2011. https://doi.org/10.1520/ C0496_C0496M-11

ASTM International. 2015. Standard Test Method for Flexural Strength of Dimension Stone (Superseded). ASTM C880/ C880M-15. West Conshohocken, PA: ASTM International, approved May 1, 2015. https://doi.org/10.1520/ C0880_C0880M-15

ASTM International. 2015. Standard Test Method for Modulus of Rupture of Dimension Stone (Superseded). ASTM C99/C99M15. West Conshohocken, PA: ASTM International, approved May 1, 2015. https://doi.org/10.1520/C0099_C0099M-15

ASTM International. 2016. Standard Test Method for Unconfined Compressive Strength of Cohesive Soil. ASTM D2166/ D2166M-16. West Conshohocken, PA: ASTM International, approved July 1, 2016. https://doi.org/10.1520/ D2166_D2166M-16

Backers, T. and O. Stephansson. 2012. "ISRM Suggested Method for the Determination of Mode II Fracture Toughness." Rock Mechanics and Rock Engineering 45, no. 6 (July): 1011-1022. https://doi.org/10.1007/s00603-012-0271-9

Billevicz, V. “Analysis of Stress in Circular Rings.” PhD diss., University of Michigan, 1931.

British Standards Institution. 2018. Geotechnical Investigation and Testing-Laboratory Testing of Soil, Part 7: Unconfined Compression Test. BS EN ISO 17892-7:2018. London: British Standards Institution, approved March 15, 2018.

Coviello, A., R. Lagioia, and R. Nova. 2005. "On the Measurement of the Tensile Strength of Soft Rocks." Rock Mechanics and Rock Engineering 38, no. 4 (June): 251-273. https://doi.org/10.1007/s00603-005-0054-7

Dismuke, T. D., W. F. Chen, and H. Y. Fang. 1972. “Tensile Strength of Rock by the Double-Punch Method.” Rock Mechanics 4, no. 2 (October): 79-87. https://doi.org/10.1007/BF01239138

Erarslan, N. and D. J. Williams. 2012. "Experimental, Numerical and Analytical Studies on Tensile Strength of Rocks." International Journal of Rock Mechanics and Mining Sciences 49 (January): 21-30. https://doi.org/10.1016/j.ijrmms. 2011.11.007

Fairhurst, C. 1964. “On the Validity of the 'Brazilian’ Test for Brittle Materials.” International Journal of Rock Mechanics and Mining Sciences and Geomechanics Abstracts 1, no. 4 (October): 535-546. https://doi.org/10.1016/0148-9062(64)90060-9

Goodman, R. E. 1989. Introduction to Rock Mechanics, 2nd ed. Singapore: Wiley.

Hardy, H. R. and N. I. Jayaraman. 1970. "An Investigation of Methods for the Determination of the Tensile Strength of Rock." International Society of Rock Mechanics, Proceedings 3, nos. 5-12: 85-92.

He, M. Y., H. C. Cao, and A. G. Evans. 1990. "Mixed-Mode Fracture: The Four Point Shear Specimen.” Acta Metallurgica et Materialia 38, no. 5 (May): 839-846. https://doi.org/10.1016/0956-7151(90)90037-H

Hiramatsu, Y. and Y. Oka. 1970. "Disc Test, Ring Test, Rectangular Plate Test and Irregular Specimen Test for Determining the Tensile Strength of Rocks.” International Society of Rock Mechanics, Proceedings 2, nos. 3-29: 199-206.

Hobbs, D. W. 1964. "The Tensile Strength of Rocks." International Journal of Rock Mechanics and Mining Sciences and Geomechanics Abstracts 1, no. 3 (May): 385-396. https://doi.org/10.1016/0148-9062(64)90005-1

Hudson, J. A. 1969. “Tensile Strength and the Ring Test." International Journal of Rock Mechanics and Mining Sciences and Geomechanics Abstracts 6, no. 1 (January): 91-97. https://doi.org/10.1016/0148-9062(69)90029-1

Hudson, J. A., E. T. Brown, and F. Rummel. 1972. “The Controlled Failure of Rock Discs and Rings Loaded in Diametral Compression." International Journal of Rock Mechanics and Mining Sciences and Geomechanics Abstracts 9, no. 2 (March): 241-248. https://doi.org/10.1016/0148-9062(72)90025-3

ISRM (International Society for Rock Mechanics). 1978. "Suggested Methods for Determining Tensile Strength of Rock Materials." International Journal of Rock Mechanics and Mining Sciences and Geomechanics Abstracts 15, no. 3 (June): 99-103. https://doi.org/10.1016/0148-9062(78)90003-7

ISRM (International Society for Rock Mechanics). 1979. "Suggested Methods for Determining the Uniaxial Compressive Strength and Deformability of Rock Materials." International Journal of Rock Mechanics and Mining Sciences and Geomechanics Abstracts 16, no. 2 (April): 137-140. https://doi.org/10.1016/0148-9062(79)91450-5

Jaeger, J. C. 1967. "Failure of Rocks under Tensile Conditions." International Journal of Rock Mechanics and Mining Sciences and Geomechanics Abstracts 4, no. 2 (April): 219-227. https://doi.org/10.1016/0148-9062(67)90046-0

Jaeger, J. C. and E. R. Hoskins. 1966. "Rock Failure under the Confined Brazilian Test.” Journal of Geophysical Research 71, no. 10 (May): 2651-2659. https://doi.org/10.1029/JZ071i010p02651

Khan, K. and N. A. Al-Shayea. 2000. "Effect of Specimen Geometry and Testing Method on Mixed Mode I-II Fracture Toughness of a Limestone Rock from Saudi Arabia." Rock Mechanics and Rock Engineering 33, no. 3 (July): $179-206$. https://doi.org/10.1007/s006030070006

Kim, T., T. Kim, G. Kang, and L. Ge. 2012. “Factors Influencing Crack-Induced Tensile Strength of Compacted Soil.” Journal of Materials in Civil Engineering 24, no. 3 (March): 315-320. https://doi.org/10.1061/(ASCE)MT.1943-5533.0000380

Kuruppu, M. D. and M. Funatsu. 2012. "Development of a Standard Method for Determining the Plane Strain Fracture Toughness of Rock." In Seventh Australasian Congress on Applied Mechanics, 877-883. Adelaide, Australia: Engineers Australia.

Mellor, M. and I. Hawkes. 1971. "Measurement of Tensile Strength by Diametral Compression of Discs and Annuli." Engineering Geology 5, no. 3 (October): 173-225. https://doi.org/10.1016/0013-7952(71)90001-9 
Ministry of Construction, People's Republic of China. 2007. Standard for Engineering Classification of Soil (in Chinese). GB/T 50145-2007. Beijing: Ministry of Construction, People's Republic of China, approved December 24, 2007.

Ministry of Housing and Urban-Rural Development, People's Republic of China. 2013. Standard for Test Methods of Engineering Rock Mass (in Chinese). GB/T 50266-2013. Beijing: Ministry of Housing and Urban-Rural Development, People's Republic of China, approved January 28, 2013.

Ministry of Housing and Urban-Rural Development, People's Republic of China. 2019. Standard for Geotechnical Test Method (in Chinese). GB/T 50123-2019. Beijing: Ministry of Housing and Urban-Rural Development, People's Republic of China, approved May 24, 2019.

Perras, M. A. and M. S. Diederichs. 2014. “A Review of the Tensile Strength of Rock: Concepts and Testing.” Geotechnical and Geological Engineering 32, no. 2 (January): 525-546. https://doi.org/10.1007/s10706-014-9732-0

Pilkey, W. D. 2005. Formulas for Stress, Strain, and Structural Matrices, 2nd ed. Hoboken, NJ: Wiley.

Price, D. G. and J. L. Knill. 1966. “A Study of the Tensile Strength of Isotropic Rocks.” In First Congress International Society for Rock Mechanics Congress, 439-442. Lisbon, Portugal: International Society for Rock Mechanics and Rock Engineering.

Sadeghi, E., M. R. Nikudel, and B. Pahlavan. 2018. "Effect of Petrological Characteristics on Tensile Strength of Limestone Using Hydraulic Fracturing Tests." International Journal of Rock Mechanics and Mining Sciences 107 (July): 120-126. https://doi.org/10.1016/j.ijrmms.2018.01.033

Timoshenko, S. 1922. "On the Distribution of Stresses in a Circular Ring Compressed by Two Forces along a Diameter.” The London, Edinburgh, and Dublin Philosophical Magazine and Journal of Science 44, no. 263: 1014-1019. https://doi.org/10. 1080/14786441208562578

Xu, S., M. H. De Freitas, and B. A. Clarke. 1988. “The Measurement of Tensile Strength or Rock.” In Rock Mechanics and Power Plants, edited by M. Romana, 125-132. Lisbon, Portugal: International Society for Rock Mechanics and Rock Engineering.

Zhu, T. and D. Huang. 2019. "Influences of the Diameter and Position of the Inner Hole on the Strength and Failure of Disc Specimens of Sandstone Determined Using the Brazilian Split Test." Journal of Theoretical and Applied Mechanics 57, no. 1 (January): 127-140. https://doi.org/10.15632/jtam-pl.57.1.127

Zoback, M. D., F. Rummel, R. Jung, and C. B. Raleigh. 1977. "Laboratory Hydraulic Fracturing Experiments in Intact and Prefractured Rock." International Journal of Rock Mechanics and Mining Sciences and Geomechanics Abstracts 14, no. 2 (March): 49-58. https://doi.org/10.1016/0148-9062(77)90196-6 